\title{
"Get Ready and Empowered About Treatment" (GREAT) Study: a Pragmatic Randomized Controlled Trial of Activation in Persons Living with HIV
}

\author{
Jennifer K. Carroll, MD, MPH' , Jonathan N. Tobin, $P h D^{2}$, Amneris Luque, MD, \\ Subrina Farah, $\mathrm{MS}^{4}$, Mechelle Sanders, $\mathrm{PhD}^{4}$, Andrea Cassells, $\mathrm{MPH}^{2}$, \\ Steven M. Fine, MD, PhD 5 , Wendi Cross, $P h D^{6}$, Michele Boyd, MPA4, \\ Tameir Holder, $\mathrm{MPH}^{2}$, Marie Thomas ${ }^{4}$, Cleo Clarize Overa, $B A^{2}$, and Kevin Fiscella, \\ $\mathrm{MD}, \mathrm{MPH}^{4,5}$
}

\begin{abstract}
'Department of Family Medicine, University of Colorado, Aurora, CO, USA; ${ }^{2}$ Clinical Directors Network, Inc. (CDN), New York, NY, USA; ${ }^{3}$ Department of Medicine, University of Texas Southwestern Medical Center, Dallas, TX, USA; ${ }^{4}$ Department of Family Medicine, Family Medicine Research Programs, University of Rochester, Rochester, NY, USA; ${ }^{5}$ Department of Family Medicine, University of Rochester, Rochester, NY, USA; ${ }^{6}$ Department of Psychiatry, University of Rochester, Rochester, NY, USA.
\end{abstract}

BACKGROUND: Little is known about strategies to improve patient activation, particularly among persons living with HIV (PLWH).

OBJECTIVE: To assess the impact of a group intervention and individual coaching on patient activation for PLWH. DESIGN: Pragmatic randomized controlled trial.

SITES: Eight practices in New York and two in New Jersey serving PLWH.

PARTICIPANTS: Three hundred sixty PLWH who received care at participating practices and had at least limited English proficiency and basic literacy.

INTERVENTION: Six 90-min group training sessions covering use of an ePersonal Health Record loaded onto a handheld mobile device and a single 20-30 min individual pre-visit coaching session.

MAIN MEASURES: The primary outcome was change in Patient Activation Measure (PAM). Secondary outcomes were changes in eHealth literacy (eHEALS), Decision Self-efficacy (DSES), Perceived Involvement in Care Scale (PICS), health (SF-12), receipt of HIV-related care, and change in HIV viral load (VL).

KEY RESULTS: The intervention group showed significantly greater improvement than the control group in the primary outcome, the PAM (difference 2.82: 95\% confidence interval [CI] 0.32-5.32). Effects were largest among participants with lowest quartile PAM at baseline $(p<0.05)$. The intervention doubled the odds of improving one level on the PAM (odds ratio 1.96; 95\% CI 1.16-3.31). The intervention group also had significantly greater improvement in eHEALS (difference 2.67: 95\% CI 1.38-3.9) and PICS (1.27: 95\% CI 0.41-2.13) than the control group. Intervention effects were similar by race/ethnicity and low education with the exception of eHealth literacy where effects were stronger for minority participants. No

Electronic supplementary material The online version of this article (https://doi.org/10.1007/s11606-019-05102-7) contains supplementary material, which is available to authorized users.

Received July 2, 2018

Revised January 10, 2019

Accepted May 1, 2019

Published online June 25, 2019 statistically significant effects were observed for decision self-efficacy, health status, adherence, receipt of HIV relevant care, or HIV viral load.

CONCLUSIONS: The patient activation intervention modestly improved several domains related to patient empowerment; effects on patient activation were largest among those with the lowest levels of baseline patient activation. TRIAL REGISTRATION: This study is registered at Clinical Trials.Gov (NCTO2165735).

KEY WORDS: patient participation; self-care; HIV; computer literacy; health literacy.

J Gen Intern Med 34(9):1782-9

DOI: $10.1007 / \mathrm{s} 11606-019-05102-7$

(c) Society of General Internal Medicine 2019

\section{BACKGROUND}

Patient activation is critical to improving patient selfmanagement and reducing avoidable emergency department visits and hospitalizations. Less recognized, however, is that social disadvantage (e.g., poverty, minority race, born outside USA, non-English speaking) contributes to disparities in health care through lower patient activation. ${ }^{1} \mathrm{HIV}$ is a prime example where low patient activation among socially disadvantaged persons living with HIV (PLWH) contributes to disparities in adherence, ${ }^{2,3}$ viral suppression, ${ }^{4,5}$ and ultimately, to disparities in HIV treatment outcomes, ${ }^{6-8}$ such as hospitalizations and mortality. ${ }^{9,}{ }^{10}$ Compared to non-Latino white and/or more affluent PLWH, poor and minority PLWH miss more office visits, ${ }^{11}$ ask fewer questions during their visits, ${ }^{12}$ report less confidence in self-management and more frequently miss doses, ${ }^{13}$ or stop taking their antiretroviral therapy. ${ }^{14}$ Death from HIV-related causes represents a top ten leading cause of death among Blacks and Latinos ages $20-54$ years. ${ }^{15}$ Among Blacks ages 35-44 years, HIV ranks in the top five causes of death. ${ }^{15}$ Therefore, improvements in patient 
activation may be an important approach to close disparities gaps in health care for PLWH.

Relatively little is known about how to improve patient activation among PLWH. ${ }^{16,17}$ Patient activation requires access to reliable health information, including from online sources and access to one's own personal health information, which is increasingly available through patient portals that are part of most electronic health records (EHR) systems. However, availability of patient portals to EHRs or even use of handheld electronic Personal Health Records (ePHRs) are unlikely to be sufficient to improve self-management, without specific support to enhance knowledge and skills. ${ }^{18,} 19$

This program was developed through community-based participatory research involving PLWH, HIV clinicians, and HIV community-based organizations. The program incorporated principles from the Stanford Chronic Disease SelfManagement Program and the Positive Self-Management Program for PLWH, i.e., small groups, staff and peer facilitation, and problem solving and self-management skill development. ${ }^{20,}{ }^{21}$ Our intervention is unique in its training in the use of self-management health technology, particularly an ePHR that prompts PLWH to initiate conversations with their clinician regarding evidence-based care or patient-determined concerns.

The primary objective of this study was to evaluate the effect of a multimodal self-management program, consisting of access to an ePHR, combined with a targeted, peer-led, and group-based intervention on patient activation for PLWH. Secondary objectives were to examine the impact of the intervention on related domains of empowerment, including improvement in eHealth literacy, decision-making, adherence, receipt of HIV preventive services, health status, and HIV viral load, including examining differences in effectiveness across disparity groups.

\section{METHODS}

A full description of the methods and protocol has been published. ${ }^{22}$ The study was approved by the Institutional Review Boards (IRBs) at University of Rochester, Clinical Directors Network, Inc. (CDN) and the Family Health Centers at NYU Langone. This trial is registered at Clinical Trials.Gov (NCT02165735).

This study, named "Get Ready and Empowered About Treatment" (GREAT), used a pragmatic randomized controlled trial (RCT) design. GREAT was grounded in the principles of Community-Based Participatory Research (CBPR), where patients and stakeholders were active partners throughout. $^{23,}{ }^{24}$ The conceptual model was based on the Capability, Opportunity, Motivation and Behavior (COM-B) model for behavior change. ${ }^{25}$ GREAT's intervention consisted of (1) a customized ePHR for PLWH using a smart device (Apple iPod $($ ) which was provided as an incentive to all participants in order to ensure they had access to the internet; (2) six 90- min, group-based, and peer-led training sessions on use of the iPod, ePHR, and web-searching for health information; and (3) a pre-visit coaching session conducted by a peer trainer. To ensure the principal of justice for the study, participants randomized to the intervention group received an iPod prior to training before follow-up measures were obtained; participants randomized to the control group received an iPod after all follow-up measures were obtained.

\section{Setting}

Eight primary care practices in New York (Rochester and the Greater New York Metropolitan Area) participated in the study. Three practices had a focus on HIV care, and five were Federally Qualified Health Centers (FQHCs) with large HIV populations. Clinicians at each site received a 1-h, CMEaccredited training session. The purpose of this training was to provide an overview of the study, prepare clinicians for activated patients, and demonstrate communication skills that are more engaging for patients.

\section{Participants}

Inclusion criteria were confirmed HIV diagnosis, age $\geq$ 18 years, and receipt of HIV/primary care at a participating site. Exclusion criteria included, prior participation in the pilot, the inability to provide informed consent or limited English proficiency. We recruited participants directly via onsite, faceto-face discussions at the time of patient visits and/or practice outreach. A research assistant contacted patients expressing interest, to describe the study procedures, explain the risks and benefits, answer questions, and obtain written, informed consent.

\section{Randomization and Allocation Procedures}

The study statistician generated sequential identification numbers (IDs) using computer-generated random numbers stratified by location of site (Rochester or Greater New York Metropolitan Area). Three hundred and sixty sequentially numbered, opaque, and sealed envelopes were created prior to participant enrollment. A research assistant opened the envelopes sequentially, after the participant had consented and completed the baseline (T0) assessment. Due to the nature of the study, neither patients nor study staff with direct contact with patients were blinded to group assignment. The investigators were blinded to participant randomization assignments.

\section{Intervention Group}

A full description of the intervention and the protocol has been published. Appendix 1 online also provides additional details. Briefly, the intervention group received a smart device (the Apple iPod Touch ( ) and a customized ePHR developed for PLWH named URHealth that we pre-loaded on each device. Key features included (1) drop down menus for common HIV medications with accompanying pill pictures; (2) common lab 
tests with brief, understandable explanations; (3) ability to set reminders for appointments, as well as for taking and refilling medications; and (4) personalized "prompt list" of potential questions for the patient to ask their clinician.

The intervention consisted of six 90-min training sessions, in groups of mean participant size $N=11$ (range 715), co-facilitated by staff coaches and trained peer educators. The sessions focused on basic HIV literacy, development of basic eHealth competency, use of the ePHR, and how to ask questions. Co-facilitators encouraged participants to assist each other in learning and to celebrate successes. Groups were not assigned based on clinician, although there was likely some natural geographic clustering based on locations of training.

After completing the group training sessions, each patient received one 20-30 min individual coaching session. A staff coach met with each patient before the patient's next HIV office visit to reinforce skills learned during the group training and to prepare participants to be engaged at their office visit including identifying questions/concerns they wished to address during the visit.

We developed a training and fidelity assessment manual for professional staff and peers to conduct the group training and individual coaching sessions. We assessed fidelity using an observation checklist based on the content that was expected to be covered during each of the six training sessions. Trained observers assessed the quality and delivery of the content elements. Fidelity ranged from 0 to 1 , with 1 being perfect fidelity. The mean fidelity scores for delivery and quality across each of the groups were 0.95 and 0.91 , respectively.

\section{Control Group}

The control group was not assigned to an intervention group and received usual care according to their practice's guidelines and resources. Most practices had case managers on staff to assist patients with barriers and to promote adherence. All control group participants also received the iPod device after their follow-up evaluation was completed.

\section{Outcomes}

Three hundred and sixty patient participants were enrolled. The primary outcome was change in patient activation at 12 months using the 13-item Patient Activation Measure which is re-scaled (0-100). Secondary measures (Table 1) included other empowerment domains, adherence, health status, viral suppression, and uptake of recommended HIVrelated preventive intervention.

Participants were assessed at baseline/time of randomization (T0), 6-8 weeks post-randomization (T1) and at 12 months post-randomization (T2). The measures were collected through survey administration (T0-T2) and chart abstraction by study research assistants (RAs) after participants completed their T2 assessments (T3). There were no changes to trial outcomes after the trial commenced.
Table 1 Baseline Characteristics of Study Participants

\begin{tabular}{|c|c|c|c|}
\hline$\overline{\text { Characteristic }}$ & $\begin{array}{l}\text { Intervention } \\
(n=180)\end{array}$ & $\begin{array}{l}\text { Control } \\
(n=179)\end{array}$ & $\begin{array}{l}p \\
\text { value }\end{array}$ \\
\hline Age, mean (SD) & $51.7(10.7)$ & $\begin{array}{l}51.2 \\
(11.3)\end{array}$ & 0.69 \\
\hline \multicolumn{3}{|l|}{$\operatorname{Sex}(\%)$} & 0.15 \\
\hline Male & 62.2 & 56.4 & \\
\hline Female & 37.8 & 41.9 & \\
\hline Transgender & 0 & 1.7 & \\
\hline \multicolumn{3}{|l|}{ Race $(\%)$} & 0.11 \\
\hline American Indian/Alaska & 0.6 & 0 & \\
\hline \multicolumn{4}{|l|}{ Native } \\
\hline Asian & 0 & 0 & \\
\hline White & 23.9 & 20.7 & \\
\hline Black or African American & 54.4 & 49.7 & \\
\hline Native Hawaiian or Other & 0 & 0 & \\
\hline \multicolumn{4}{|l|}{ Pacific Islander } \\
\hline More than one race & 10.0 & 6.7 & \\
\hline Other & 8.9 & 16.7 & \\
\hline Unknown or not reported & 2.2 & 6.7 & \\
\hline Latino ethnicity $(\%)$ & 20.0 & 26.3 & 0.16 \\
\hline \multicolumn{3}{|l|}{ Insurance type $(\%)$} & 0.70 \\
\hline Private & 7.2 & 8.4 & \\
\hline Medicare & 28.3 & 24.0 & \\
\hline Medicaid & 77.8 & 77.1 & \\
\hline ADAP & 11.1 & 13.4 & \\
\hline Other & 7.2 & 6.7 & \\
\hline \multirow{2}{*}{\multicolumn{3}{|c|}{ Monthly income (\%) }} & \\
\hline & & & 0.88 \\
\hline$\$ 0$ to $\$ 999$ & 70.0 & 67.6 & \\
\hline$\$ 1000$ to $\$ 1999$ & 21.1 & 23.5 & \\
\hline$\$ 2000$ and over & 8.9 & 8.9 & \\
\hline \multicolumn{3}{|l|}{ Education $(\%)$} & 0.66 \\
\hline Less than high school & 28.9 & 31.3 & \\
\hline $\begin{array}{l}\text { High school diploma/GED } \\
\text { or equivalent }\end{array}$ & 31.1 & 28.5 & \\
\hline $\begin{array}{l}\text { Some college (no degree) or } \\
\text { technical school }\end{array}$ & 20.6 & 24.0 & \\
\hline Associate degree & 10.6 & 6.7 & \\
\hline \multirow{2}{*}{\multicolumn{3}{|c|}{ Frequency of computer use }} & \\
\hline & & & 0.79 \\
\hline Missing & 0 & 1 & \\
\hline Never & 25.1 & 25.1 & \\
\hline \multicolumn{3}{|l|}{$\begin{array}{l}\text { Frequency of Internet use } \\
(\%)\end{array}$} & 0.23 \\
\hline Number missing & 0 & 2 & \\
\hline Never & 17.3 & 23.0 & \\
\hline \multicolumn{3}{|l|}{$\begin{array}{l}\text { Familiarity with an iPod, an } \\
\text { iPad or an iPhone }\end{array}$} & 0.89 \\
\hline Number missing & 0 & 2 & \\
\hline Never heard of it & 1.1 & 1.7 & \\
\hline \multicolumn{4}{|l|}{ used one } \\
\hline I've used one a few times & 18.4 & 18.5 & \\
\hline I previously owned one & 12.3 & 14 & \\
\hline I currently own one & 14.5 & 16.9 & \\
\hline No. of visits/year & $5.6(3.5)$ & $5.4(3.4)$ & 0.66 \\
\hline Undetectable viral load (\%) & 76.7 & 75.4 & 0.78 \\
\hline \multicolumn{4}{|c|}{ Baseline outcome measures, mean (SD) } \\
\hline Patient Activation & $72.15(16.70)$ & 70.78 & 0.21 \\
\hline $\begin{array}{l}\text { Measure }^{26} \\
\text { eHealth Literacy Scale }\end{array}$ & $28.53(7.75)$ & $\begin{array}{l}(15.57) \\
27.27 \\
(8.52)\end{array}$ & 0.14 \\
\hline \multicolumn{2}{|l|}{$\begin{array}{l}\text { Decision Self-Efficacy } \\
\text { Scale }^{28}\end{array}$} & $\begin{array}{l}90.76 \\
(12.03)\end{array}$ & 0.41 \\
\hline Perceived Involvement in & $30.58(5.89)$ & 30.17 & 0.25 \\
\hline \multicolumn{2}{|l|}{ Care Scale $^{29}$} & $(5.59)$ & \\
\hline Instrument on Doctor & $85.07(13.50)$ & 82.63 & 0.07 \\
\hline Patient Communication & & $(17.00)$ & \\
\hline Skills $^{30}$ & & & \\
\hline HIV Adherence Self- & $101.27(18.49)$ & 100.84 & 0.58 \\
\hline Efficacy Scale $^{31}$ & & (19.54) & \\
\hline SF-12 (mental) ${ }^{32}$ & $45.93(11.15)$ & $\begin{array}{l}45.99 \\
(11.04)\end{array}$ & 0.52 \\
\hline $\begin{array}{l}\text { SF-12 } \\
\text { (physical)_ENREF_54 }\end{array}$ & $43.15(12.76)$ & $\begin{array}{l}44.80 \\
(12.17)\end{array}$ & 0.89 \\
\hline
\end{tabular}




\section{Sample Size}

We aimed to detect a medium ( 0.5$)$ effect size with $80 \%$ power at two-tailed significance level of 0.05 using the method described by Donner and Klar. ${ }^{33}$ The intracluster correlation (ICC $=0.0207$ ) was estimated from our pilot data and is consistent with other studies. ${ }^{34}$ Based on these assumptions, including intracluster correlation ( $\mathrm{ICC}=0.02$ ) from our pilot and an estimated $15 \%$ drop-out rate, we estimated we needed to enroll 360 participants.

\section{Statistical Analysis}

We compared changes in patient outcomes using generalized estimating equation (GEE) models that controlled for clustering by site and within cohort. All models were adjusted for any potential confounders. We entered the intervention effect (three time points) as an interaction term (months). We imputed missing values $(<1 \%)$ using multiple imputation. ${ }^{35,36}$ To assess the potential impact of extreme values, we conducted sensitivity analyses in which we excluded participants who consistently reported extreme values for a particular scale. For secondary outcomes, we used Bonferroni correction for multiple comparisons.

We used mixed effects models to control for site effects and patient characteristics. Undetectable viral loads were used as binary outputs in GEE models controlling for covariates, site, and cohort. To measure the effect of evidence-based preventive care between intervention and control groups, a structured algorithm was used to generate a count as an outcome variable using 11 preventive care measures: HPV, influenza, tetanus, hepatitis $\mathrm{A}, \mathrm{B}, \mathrm{C}$ testing, hepatitis $\mathrm{A}$ and $\mathrm{B}$ vaccinations, cervical cancer screening (PAP), mammography, and any colon cancer screening.

To assess for differences within subgroups, we entered interaction terms for randomized group $\times$ relevant subgroup into the models. Specifically, interaction terms were entered for race/ethnicity, education, and cut points for lowest quartile for PAM and eHealth literacy. When the interaction term was significant $(p<0.05)$, we conducted stratified analyses to assess the impact of the intervention on these subgroups. All statistical analyses were conducted using SAS (Cary, NC) version 9.4.

\section{RESULTS}

\section{Study Participants}

Participant enrollment began in July 2014 and the trial ended in March 2017. Figure 1 shows the participant flow through the study. A total of 694 participants were screened for eligibility, 471 met eligibility criteria, and 360 were randomized. Primary reasons for ineligibility were being HIV negative and prior participation in the pilot (Fig. 1). The participants enrolled were predominantly female (40\%), African American $(52 \%)$, Latino/a (23\%), uninsured (2\%), or had Medicaid
(77\%). Thirty percent of participants did not graduate from high school or hold a GED. Ninety-one percent had incomes of less than $\$ 2000 /$ month. One in four participants had never used a computer. The intervention and usual care groups were well-matched (Table 1).

\section{Adherence to the Intervention}

Eighty-four percent of the intervention group attended at least one of the group training sessions. The mean number of sessions attended was four (out of a possible six). Thirty-six percent required extra help, or missed a session and met individually with a trainer. Three of four participants $(76 \%)$ attended the pre-visit, individual coaching sessions.

We assessed use of the URHealth app by identifying IDs of app use during the training sessions among those assigned to the intervention and assessing frequency of login and screen use. One hundred thirty-three participants ( $74 \%$ of those in the intervention group) used the app at least once. One hundred nine participants ( $61 \%$ of the intervention group) used the app at least once in the 6 months after their training (control participants did not have access to the app during the study). Of the 109 participants who used the app post training, $61 \%$ used it for a mean of 18 times and had a mean usage time of $131 \mathrm{~min}$. In order of frequency, the most commonly opened screens were tests, events, and to-do list (which included the question prompts).

\section{Outcomes}

Table 2 shows the unadjusted changes in mean PAM scores among participants by baseline PAM level and time. Participants with baseline PAM levels of 2-4 performed significantly better in the intervention than the control condition. Level 4 participants in both groups showed declines in PAM scores from baseline, presumably due to regression to the mean.

In mixed models that controlled for patient characteristics and clustering of patients by cohort and by site, the intervention yielded statistically significant effects corresponding to a 2.83-unit improvement in patient activation (Table 3). Specifically, patient activation improved at 12 months to $73.35 \pm 1.13$ and $70.53 \pm 1.14$ in the intervention and usual care groups, respectively $(p=0.0271)$. Moreover, the intervention was found to have a moderating effect on PAM level. The interaction between the intervention and PAM level was statistically significant among those in the lowest PAM quartile at baseline $(p<0.05)$. In sensitivity analyses, results remained significant when extreme values were omitted. Notably, the intervention was associated with double the odds of improving one PAM level compared with control (odds ratio 1.96; 95\% CI 1.16-3.31).

Results were not statistically significant for decision self-efficacy, patient perception of clinician communication, adherence self-efficacy or adherence, viral 


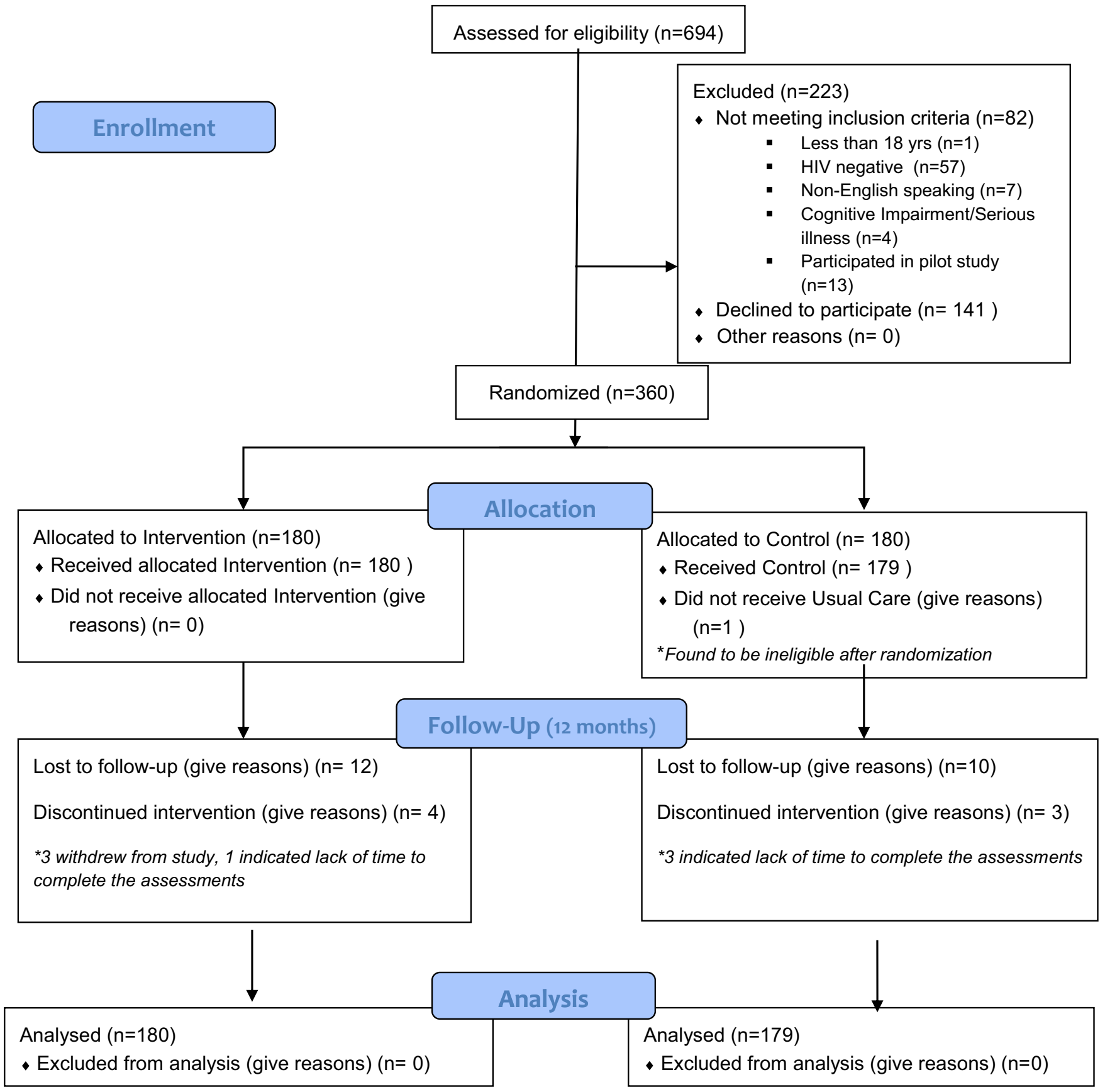

Fig. 1 The GREAT study participant flow diagram.

suppression, receipt of HIV preventive services, or change in physical or mental health status (Table 3). However, the intervention improved eHealth literacy and patient perceptions of involvement in care.

There were no statistically significant interactions by race/ ethnicity or education for the intervention's effects on the PAM. We observed a statistically significant interaction in eHealth literacy for minority patients. Stratified analysis by minority race showed that minority patients had statistically significant greater improvement in eHealth literacy than nonminority patients.

\section{DISCUSSION}

We found that a multimodal patient self-management group eHealth intervention, co-facilitated by peer trainers for PLWH, modestly improved patient activation and other measures of patient empowerment. Effects were seen across race/ethnicity and education. This improvement in PAM level is clinically relevant. Patients in the lowest level are significantly more likely to develop a new chronic disease in the 3 years of observation with odds ratios ranging from 1.21 to 1.31 compared to those with the highest level. ${ }^{37}$ Improvements in PAM levels are associated with lower odds of having an emergency 
Table 2 Unadjusted Changes in PAM Score by Baseline Level and Time

\begin{tabular}{|c|c|c|c|c|c|c|c|c|}
\hline \multirow[t]{2}{*}{ PAM levels at T0 } & & \multicolumn{3}{|c|}{ Control (C) } & \multicolumn{3}{|c|}{ Intervention (I) } & \multirow{2}{*}{$\begin{array}{l}\text { Difference between T0 vs T2 } \\
\text { by arms } \\
p \text { value }\end{array}$} \\
\hline & & T0 & T1 & $\mathbf{T 2}$ & T0 & T1 & $\mathbf{T 2}$ & \\
\hline $\begin{array}{l}\text { Level } 1^{*}(n=20, C=12, \\
\text { I=8) } \\
\text { Level } 2^{\dagger}(n=41, C=16, \\
I=25) \\
\text { Level } 3^{\ddagger}(n=114, C= \\
61, I=53) \\
\text { Level } 4^{\S}(n=184, C= \\
90, I=94)\end{array}$ & $\begin{array}{l}\text { Mean } \\
\text { (SD) } \\
\text { Mean } \\
\text { (SD) } \\
\text { Mean } \\
\text { (SD) } \\
\text { Mean } \\
\text { (SD) }\end{array}$ & $\begin{array}{l}43.6 \\
(1.8) \\
50.6 \\
(2.5) \\
63.1 \\
(4.9) \\
83.2 \\
(9.9)\end{array}$ & $\begin{array}{l}56.7 \\
(16.5) \\
60.0 \\
(9.7) \\
67.4 \\
(15.1) \\
77.9 \\
(14.3)\end{array}$ & $\begin{array}{l}54.6 \\
(11.8) \\
59.3 \\
(8.3) \\
66.8 \\
(14.8) \\
79.0 \\
(14.8)\end{array}$ & $\begin{array}{l}43.1 \\
(2.5) \\
50.0 \\
(2.4) \\
63.2 \\
(5.3) \\
85.6 \\
(9.3)\end{array}$ & $\begin{array}{l}55.8 \\
(11.2) \\
65.4 \\
(13.1) \\
66.5 \\
(14.9) \\
81.0 \\
(14.1)\end{array}$ & $\begin{array}{l}57.8 \\
(6.6) \\
66.3 \\
(9.8) \\
69.9 \\
(14.1) \\
82.8 \\
(13.6)\end{array}$ & $\begin{array}{l}\mathbf{0 . 0 0 0 8} \\
0.05\end{array}$ \\
\hline
\end{tabular}

Bolded numbers refer to statistically significant values, i.e. $p<0.05$

$S D$ unadjusted standard deviation

* Level 1 (0-47): lack of confidence to play an active role in their health

tLevel 2 (47.1-55.1): building knowledge and confidence, but still struggling with adherence

Hevel 3 (55.2-72.4): taking action to become a more active patient

${ }^{\xi}$ Level 4 (72.5-100): maintaining activation and confidence, although still struggling at times

department visit ${ }^{38}$ and lower health care costs among highcost patients. ${ }^{39}$ These findings suggest greater costeffectiveness when targeting patients at increased risk for high costs. Moreover, the intervention was successful in engaging patients in use of the ePHR with a variety of educational levels and variable rates of prior electronic technology use. However, during the 12-month follow-up period, the intervention did not show statistically significant improvement in adherence to
ART, viral suppression, receipt of HIV preventive care, or health status.

To our knowledge, this is the first randomized controlled trial of an intervention that was explicitly designed to improve patient activation using eHealth technology among predominantly low-income PLWH. The intervention was designed to provide PLWH not only with knowledge and confidence in managing their health and health care but also with the skills

Table 3 Effect of the GREAT Intervention on 12-Month Outcomes

\begin{tabular}{|c|c|c|c|c|c|c|c|c|}
\hline \multirow[t]{2}{*}{ Outcomes } & \multicolumn{2}{|c|}{ Intervention } & \multicolumn{2}{|c|}{ Control } & \multirow[t]{2}{*}{ Coefficient estimates } & \multicolumn{2}{|c|}{$\begin{array}{l}\text { 95\% CI lower } \\
\text { upper }\end{array}$} & \multirow[t]{2}{*}{$p$ value } \\
\hline & Mean & SD & Mean & SD & & & & \\
\hline \multicolumn{9}{|l|}{ Measures } \\
\hline \multicolumn{9}{|l|}{ Primary outcome } \\
\hline Patient Activation Measure (PAM) ${ }^{\dagger}$ & 73.35 & 1.13 & 70.53 & 1.14 & 2.82 & 0.32 & 5.32 & 0.0271 \\
\hline \multicolumn{9}{|l|}{ Secondary empowerment outcomes } \\
\hline eHealth Literacy Scale ${ }^{\dagger}$ & 29.81 & 1.45 & 27.67 & 1.42 & 2.67 & 1.38 & 3.95 & $<0.0001$ \\
\hline Decision Self-Efficacy Scale ${ }^{\dagger}$ & 91.89 & 0.86 & 90.81 & 0.87 & 1.09 & -0.82 & 3.00 & 0.2631 \\
\hline Perceived Involvement in Care Scale ${ }^{\dagger}$ & 33.74 & 0.94 & 32.47 & 0.90 & 1.27 & 0.41 & 2.13 & 0.0038 \\
\hline Perceived Clinician Communication (IDPCS) $)^{\S}$ & 85.06 & 1.24 & 83.49 & 1.25 & 3.18 & 0.01 & 6.35 & 0.0490 \\
\hline \multicolumn{9}{|l|}{ HIV adherence and viral suppression } \\
\hline HIV Adherence Self-Efficacy Scale & 102.80 & 1.08 & 103.13 & 1.07 & -0.33 & -3.26 & 2.60 & 0.8251 \\
\hline Self-reported adherence & 89.33 & 1.09 & 89.90 & 1.09 & -0.56 & -3.44 & 2.32 & 0.7014 \\
\hline Undetectable viral load* & $87 \%$ & $3.1 \%$ & $86 \%$ & $3.1 \%$ & 0.00 & -0.06 & 0.07 & 0.9113 \\
\hline \multicolumn{9}{|l|}{ Receipt of HIV-related care and preventive services } \\
\hline Index & 0.35 & 0.01 & 0.35 & 0.02 & -0.01 & -0.05 & 0.05 & 0.9937 \\
\hline \multicolumn{9}{|l|}{ Health status } \\
\hline SF-12 (mental) & 46.38 & 0.73 & 46.99 & 0.73 & -0.61 & -2.29 & 1.08 & 0.4787 \\
\hline SF-12 (physical) & 44.83 & 0.71 & 45.13 & 0.72 & -0.30 & -2.29 & 1.66 & 0.7625 \\
\hline \multicolumn{9}{|l|}{ Interactions } \\
\hline PAM: low PAM $\times$ arm & & & & & & & & 0.0175 \\
\hline PAM: minority race $\times \operatorname{arm}^{\S}$ & & & & & & & & 0.9998 \\
\hline PAM: low education $\times$ arm & & & & & & & & 0.1504 \\
\hline PAM: IDPCS $\times$ arm & & & & & & & & 0.5389 \\
\hline eHEALS: minority race $\times \operatorname{arm}^{\S}$ & & & & & & & & 0.0275 \\
\hline eHEALS: low education $\times$ arm & & & & & & & & 0.5509 \\
\hline
\end{tabular}

Bolded numbers refer to statistically significant values, i.e. $p<0.05$

IDPCS Instrument on Doctor Patient Communication Skills, SF-12 Short Form Health Survey: Physical and Mental Health

*Percent of patients with testing whose viral load was undetectable

${ }^{\dagger}$ Significance between arms at $\alpha=0.05$ (all remained significant after Bonferroni correction for secondary measures $(p<0.0047$ ) except IDPCS which was no longer statistically significant)

${ }^{7}$ For mixed model calculation, arms, cohort, timeline, race, ethnicity, gender, age, computer use, education, familiarity with an iPod, an iPad or iPhone, income, internet use, and marital status have been considered

${ }^{s}$ minority race $=$ non-white ( $v$ s white/non-Hispanic), low education $=<$ high school ( $v s>$ high school), low PAM $=$ bottom quartile (vs remainder), low eHEALS = bottom quartile (vs remainder) 
and tools, i.e., a mobile device with an online personal eHealth record, to facilitate self-management. Our intervention builds on previous chronic self-management programs through its integration of training and use of handheld EHR and by training patients to ask their clinicians relevant questions, showing improvements in eHealth literacy in addition to patient activation.

Other trials have assessed patient activation interventions for patients with other conditions, e.g., diabetes, heart failure, prevention, and hypertension. ${ }^{40-49}$ Participants in GREAT had high mean baseline PAM scores, and their PAM scores were higher than those reported in several other studies. ${ }^{50-52}$

Because our study population had relatively high levels of baseline PAM scores and high ART adherence and viral load suppression, there may have been limited room for improvement ("ceiling effect"). High PAM scores are associated with improved health outcomes, quality of life and healthy lifestyle behaviors. Additionally, we recruited patients from practices with established, relatively robust clinical and care management/support services available for PLWH, which could have attenuated the effect of the intervention. Therefore, it may have been difficult to observe changes in quality of life, viral load outcomes, and other preventive care measures in this intervention during the 12 month follow-up; these changes may require a longer follow-up interval to discern. These findings point to the need to tailor activation interventions to increase skills and confidence for different self-management tasks for those with varying levels of activation. However, our findings also suggest that patient activation training alone, even when provided in groups and accompanied by eHealth tools, may not be sufficiently potent to improve adherence for patients with detectable viral loads. Additional ART adherence training may be needed for the small minority of patients whose HIV viral loads are not suppressed. ${ }^{53,54}$

Future research should explore use of patient EHR portals that provide personally tailored prompts to patients regarding topics for discussion with their clinician. Research is also needed to replicate our findings among non-HIV+ low-income patients with low eHealth technology use and to assess the costeffectiveness of this multimodal approach to patient activation.

\section{Limitations}

This study had a relatively short duration of the intervention for the outcomes studied. Also, outcome assessments were not blinded introducing possible bias particularly for self-report measures. The sample was limited to English fluent persons with PLWH who received care in participating sites in Rochester, NY, and the NYC area, potentially limiting generalizability to other chronic conditions or groups served in other geographic locations. By design, there was limited involvement of clinicians and practices. Future studies should consider enhancing clinician engagement. Cross contamination by clinicians (all of whom received the 60-min training) may have biased results towards the null. While participants were coached before a visit with their HIV clinician, a single visit may not have been sufficient to address the combination of prompted questions from the ePHR and the patient's own primary concerns.

In summary, this patient activation intervention modestly improved several domains related to patient empowerment. No effects were observed for health status, adherence, receipt of HIV relevant care, or HIV viral load.

Acknowledgments: Participating sites: Family Health Centers at NYU Langone, Brooklyn, NY; Horizon Health Center (Alliance Community Healthcare), Jersey City, NJ; Metropolitan Family Health Network, Jersey City, NJ; Morris Heights Health Center, Bronx, NY; Anthony Jordan Health Center, Rochester, NY; Strong Memorial Hospital/Infectious Diseases, Rochester, NY; Trillium Health, Rochester, NY; and Rochester Regional Health/Unity Hospital, Rochester, NY.

Corresponding Author: Kevin Fiscella, MD, MPH; Department of Family Medicine, Family Medicine Research Programs University of Rochester, Rochester, NY, USA (e-mail: Kevin_fiscella@urmc.rochester. edu).

Authors' Contributions All authors listed have contributed suffciently to the project to be included as authors, and all those who are qualified to be authors are listed in the author byline.

Funding Patient-Centered Outcomes Research Institute [Grant\# $A D$ 1306-03104]

\section{Compliance with Ethical Standards:}

Conflict of Interest: The authors declare that they do not have a conflict of interest.

\section{REFERENCES}

1. Cooper-Patrick L, Gallo JJ, Gonzales JJ, et al. Race, gender, and partnership in the patient-physician relationship. JAMA. 1999;282(6):583-589.

2. Crystal S, Sambamoorthi U, Moynihan PJ, McSpiritt E. Initiation and continuation of newer antiretroviral treatments among medicaid recipients with AIDS. J Gen Intern Med. 2001;16(12):850-859.

3. Pence BW, Ostermann J, Kumar V, Whetten K, Thielman N, Mugavero MJ. The influence of psychosocial characteristics and race/ethnicity on the use, duration, and success of antiretroviral therapy. J Acquir Immune Defic Syndr. 2008;47(2):194-201.

4. Skarbinski J, Johnson C, Frazier E, Beer L, Valverde E, Heffelfinger J. Nationally representative estimates of the number of $\mathrm{HIV}^{+}$adults who received medical care, were prescribed ART, and achieved viral suppression, Medical Monitoring Project, 2009 to 2010 US. Paper presented at: 19th Conference on Retroviruses and Opportunistic Infections.

5. Yehia BR FJ, Metlay JP, Moore RD, Gebo KA. Sustained viral suppression in HIV-infected patients receiving antiretroviral therapy. JAMA. 2012;308(4):339-342.

6. Hellinger FJ. The changing pattern of hospital care for persons living with HIV: 2000 through 2004. J Acquir Immune Defic Syndr: JAIDS. 2007;45(2):239-246.

7. Silverberg MJ, Leyden W, Guesenberry CP Jr, Horberg MA. Race/ ethnicity and risk of AIDS and death among HIV-infected patients with access to care. J Gen Intern Med. 2009;24(9):1065-1072.

8. French AL, Gawel SH, Hershow $\mathbf{R}$, et al. Trends in mortality and causes of death among women with HIV in the United States: a 10-year study. J Acquir Immune Defic Syndr. 2009;51(4):399-406.

9. Puhan MA, Van Natta ML, Palella FJ, Addessi A, Meinert C, Group OCoAR. Excess mortality in patients with AIDS in the era of highly active antiretroviral therapy: temporal changes and risk factors. Clin Infect Dis. 2010;51(8):947-956. 
10. Antiretroviral Therapy Cohort Collaboration, Zwahlen M, Harris R, et al. Mortality of HIV-infected patients starting potent antiretroviral therapy: comparison with the general population in nine industrialized countries. Int J Epidemiol. 2009;38(6): 1624-1633.

11. Mugavero MJ, Lin HY, Allison JJ, et al. Racial disparities in HIV virologic failure: do missed visits matter? J Acquir Immune Defic Syndr. 2009;50(1): 100-108.

12. Beach MC, Saha S, Korthuis PT, et al. Differences in patient-provider communication for Hispanic compared to non-Hispanic white patients in HIV care. J Gen Intern Med. 2010;25(7):682-687.

13. Heckman BD, Catz SL, Heckman TG, Miller JG, Kalichman SC. Adherence to antiretroviral therapy in rural persons living with HIV disease in the United States. AIDS Care. 2004;16(2):219-230.

14. Johnson MO, Chesney MA, Neilands TB, et al. Disparities in reported reasons for not initiating or stopping antiretroviral treatment among a diverse sample of persons living with HIV. J Gen Intern Med. 2009;24(2):247-251.

15. Centers for Disease Control and Prevention. Deaths, percent of total deaths, and death rates for the 15 leading causes of death in 10-year age groups, by Hispanic origin, race for non-Hispanic population and sex: United States, 2014. Available at: http://www.cdc.gov/nchs/data/dvs/ LCWK5_2008.pdf. Accessed March 27, 2019.

16. Crouch P-CB, Rose CD, Johnson M, Janson SL. A pilot study to evaluate the magnitude of association of the use of electronic personal health records with patient activation and empowerment in HIV-infected veterans. PeerJ. 2015;3:e852.

17. McInnes DK, Shimada SL, Midboe AM, et al. Patient use of electronic prescription refill and secure messaging and its association with undetectable HIV viral load: a retrospective cohort study. J Med Internet Res. 2017;19(2).

18. Ko H, Turner T, Jones C, Hill C. Patient-held medical records for patients with chronic disease: a systematic review. Qual Saf Health Care 2010;19(5):e41.

19. Tenforde $\mathbf{M}$, Jain A, Hickner J. The value of personal health records for chronic disease management: what do we know? Fam Med. 2011;43(5):351-354.

20. Lorig KR, Holman H. Self-management education: history, definition, outcomes, and mechanisms. Ann Behav Med. 2003;26(1):1-7.

21. Webel AR, Holzemer WL. Positive self-management program for women living with HIV: a descriptive analysis. J Assoc Nurses AIDS Care. 2009;20(6):458-467.

22. Fiscella K, Boyd M, Brown J, et al. Activation of persons living with HIV for treatment, the GREAT study. BMC Public Health. 2015;15:1056.

23. Luque AE, Corales R, Fowler RJ, et al. Bridging the digital divide in HIV care: a pilot study of an iPod personal health record. J Int Assoc Physicians AIDS Care (Chic). 2012.

24. Luque EA, van Keken A, Winters P, Keefer CM, Sanders M, Fiscella K. Barriers and facilitators of online patient portals to personal health records among persons living with HIV: formative research. JMIR Res Protoc. 2013;2(1):e8.

25. Michie S, van Stralen MM, West $\mathbf{R}$. The behaviour change wheel: a new method for characterising and designing behaviour change interventions. Implementation science : IS. 2011;6:42

26. Hibbard JH, Mahoney ER, Stockard J, Tusler M. Development and testing of a short form of the patient activation measure. Health Serv Res. 2005;40(6:Pt 1):t-30.

27. Norman CD, Skinner HA. eHEALS: the eHealth Literacy Scale. J Med Internet Res. 2006;8(4):e27.

28. Cranney A, O'Connor AM, Jacobsen MJ, et al. Development and pilot testing of a decision aid for postmenopausal women with osteoporosis. Patient Educ Couns. 2002;47(3):245-255.

29. Lerman CE, Brody DS, Caputo GC, Smith DG, Lazaro CG, Wolfson HG Patients' perceived involvement in care scale: relationship to attitudes about illness and medical care. J Gen Intern Med. 1990;5(1):29-33.

30. Campbell C, Lockyer J, Laidlaw T, MacLeod H. Assessment of a matched-pair instrument to examine doctor-patient communication skills in practising doctors. Med Educ. 2007;41(2):123-129.

31. Johnson MO, Neilands TB, Dilworth SE, Morin SF, Remien RH, Chesney MA. The role of self-efficacy in HIV treatment adherence: validation of the HIV Treatment Adherence Self-Efficacy Scale (HIVASES). J Behav Med. 2007;30(5):359-370.

32. Gandek B, Ware JE, Aaronson NK, et al. Cross-validation of item selection and scoring for the SF-12 Health Survey in nine countries: results from the IQOLA Project. International Quality of Life Assessment. J Clin Epidemiol. 1998;51(11):1171-1178.
33. Donner A, Klar N. Statistical considerations in the design and analysis of community intervention trials. J Clin Epidemiol. 1996;49(4):435-439.

34. Thompson DM, Fernald DH, Mold JW. Intraclass correlation coefficients typical of cluster-randomized studies: estimates from the Robert Wood Johnson Prescription for Health Projects. Ann Fam Med. 2012;10(3):235240.

35. Rubin DB. Multiple imputation after 18+ years. J Am Stat Assoc. 1996;91(434):473-489.

36. Institute P-COR. The PCORI methodology report. 2013

37. Hibbard JH, Greene J, Sacks RM, Overton V, Parrotta C. Improving population health management strategies: identifying patients who are more likely to be users of avoidable costly care and those more likely to develop a new chronic disease. Health Serv Res. 2017;52(4):1297-1309.

38. Greene J, Hibbard JH, Sacks R, Overton V, Parrotta CD. When patient activation levels change, health outcomes and costs change, too. Health Aff (Millwood). 2015;34(3):431-437.

39. Lindsay A, Hibbard JH, Boothroyd DB, Glaseroff A, Asch SM. Patient activation changes as a potential signal for changes in health care costs: cohort study of US high-cost patients. J Gen Intern Med. 2018.

40. Shively MJ, Gardetto NJ, Kodiath MF, et al. Effect of patient activation on self-management in patients with heart failure. J Cardiovasc Nurs. 2013;28(1):20-34.

41. Frias J, Virdi NS, Raja $\mathbf{P}$, et al. Evaluation of a digital health offering to optimize blood pressure and lipid control in patients with uncontrolled hypertension and type 2 diabetes: a pilot, cluster randomized study. 2016;134(1).

42. Wagner PJ, Dias J, Howard S, et al. Personal health records and hypertension control: a randomized trial. J Am Med Inform Assoc. 2012

43. Nagykaldi Z, Aspy CB, Chou A, Mold JW. Impact of a wellness portal on the delivery of patient-centered preventive care. J Am Board Fam Med. 2012;25(2): 158-167.

44. Wolever R, Dreusicke M, Fikkan J, et al. Integrative health coaching for patients with type 2 diabetes a randomized clinical trial. Diabetes Educ. 2010;36(4):629-639.

45. Lorig K, Ritter PL, Laurent DD, et al. Online diabetes self-management program. Diabetes Care. 2010;33(6):1275-1281.

46. Lorig K, Ritter PL, Villa FJ, Armas J. Community-based peer-led diabetes self-management: a randomized trial. Diabetes Educ. 2009;35(4):641-651.

47. Deen D, Lu WH, Weintraub MR, Maranda MJ, Elshafey S, Gold MR. The impact of different modalities for activating patients in a community health center setting. Patient Educ Couns. 2012;89(1):178-183.

48. Rygg LO, Rise MB, Gronning K, Steinsbekk A. Efficacy of ongoing group based diabetes self-management education for patients with type 2 diabetes mellitus. A randomised controlled trial. Patient Educ Couns. 2012;86(1):98-105.

49. Maindal HT, Sandbaek A, Kirkevold M, Lauritzen T. Effect on motivation, perceived competence, and activation after participation in the "Ready to Act" programme for people with screen-detected dysglycaemia: a 1-year randomised controlled trial, Addition-DK. Scand $\mathrm{J}$ of Soc Med. 2011;39(3):262-271

50. Becker ER, Roblin DW. Translating primary care practice climate into patient activation: the role of patient trust in physician. Med Care. 2008;46(8):795-805

51. Hendriks $\mathbf{M}$, Rademakers $\mathbf{J}$. Relationships between patient activation, disease-specific knowledge and health outcomes among people with diabetes; a survey study. BMC Health Serv Res. 2014;14:393.

52. Hibbard JH, Stockard J, Mahoney ER, Tusler M. Development of the Patient Activation Measure (PAM): conceptualizing and measuring activation in patients and consumers. Health Serv Res. 2004;39(4 Pt 1): 1005-1026.

53. Gross R, Bellamy SL, Chapman J, et al. Managed problem solving for antiretroviral therapy adherence: a randomized trial. JAMA Intern Med. 2013;173(4):300-306

54. de Bruin M, Oberjé EJ, Viechtbauer W, et al. Effectiveness and costeffectiveness of a nurse-delivered intervention to improve adherence to treatment for HIV: a pragmatic, multicentre, open-label, randomised clinical trial. Lancet Infect Dis. 2017.

Publisher's Note Springer Nature remains neutral with regard to jurisdictional claims in published maps and institutional affiliations. 